\title{
Early detection of nonperitoneal recurrence may contribute to survival benefit after curative gastrectomy for gastric cancer
}

\author{
Keiichi Fujiya $^{1} \cdot$ Masanori Tokunaga $^{1} \cdot$ Rie Makuuchi $^{1} \cdot$ Noriyuki Nishiwaki $^{1} \cdot$ \\ Hayato Omori ${ }^{1} \cdot$ Wataru Takagi $^{1} \cdot$ Fumiko Hirata $^{1} \cdot$ Makoto Hikage $^{1}$. \\ Yutaka Tanizawa $^{1} \cdot$ Etsuro Bando $^{1} \cdot$ Taiichi Kawamura $^{1} \cdot$ Masanori Terashima $^{1}$ (])
}

Received: 25 August 2016/Accepted: 15 October 2016/Published online: 24 October 2016

(c) The International Gastric Cancer Association and The Japanese Gastric Cancer Association 2016

\begin{abstract}
Background There is no evidence that strict follow-up using cross-sectional imaging after curative gastrectomy benefits survival; however, nonperitoneal recurrence detected early might be treated with additional surgery. The present study examined whether early detection of recurrence by imaging modalities could increase survival, particularly in patients with nonperitoneal recurrence.

Methods We retrospectively analyzed 218 patients with recurrent gastric cancer after curative gastrectomy performed from 2002 to 2014. The patients were divided into an asymptomatic group $(n=117)$ and a symptomatic group ( $n=101$ ), according to the presence of symptoms at the time of recurrence, to compare clinicopathological characteristics and long-term survival.

Results Peritoneal recurrence was less frequent in the asymptomatic group (22.2\%) than in the symptomatic group (62.4\%), the median time to recurrence was shorter (12.7 months vs 18.9 months; $P<0.001$ ), and the median survival time after recurrence was longer (18.7 months vs 7.5 months; $P<0.001$ ). In the asymptomatic group, 10 of 117 patients $(8.5 \%)$ received additional curative surgery after recurrence. Median overall survival after gastrectomy was not significantly different between the groups (30.1 months for the asymptomatic group vs 30.0 months for the symptomatic group; $P=0.132$ ); however, it was significantly longer among asymptomatic patients with
\end{abstract}

Masanori Terashima

m.terashima@scchr.jp

1 Division of Gastric Surgery, Shizuoka Cancer Center, 1007

Shimonagakubo, Nagaizumi-cho, Sunto-gun,

Shizuoka 411-8777, Japan nonperitoneal recurrence compared with symptomatic patients (35.9 months vs 24.0 months; $P=0.039$ ).

Conclusions The presence of symptoms at recurrence did not affect survival in patients with recurrent gastric cancer. However, detection of nonperitoneal recurrence before the appearance of symptoms may provide survival benefit. Therefore, regular follow-up, including use of imaging modalities, is recommended.

Keywords Chemotherapy · Computed tomography · Follow-up $\cdot$ Hematogenous recurrence $\cdot$ Hepatectomy

\section{Introduction}

Gastric cancer is the fifth commonest malignancy in the world [1]. Gastrectomy with D2 lymphadenectomy is considered a standard procedure for advanced gastric cancer in Western and Eastern countries [2], although the most suitable examination and frequency of follow-up to detect recurrence after gastrectomy remains controversial [3]. The European Society of Medical Oncology recommends evaluation by patient-led self-referral without regular examination [4]. On the other hand, International Gastric Cancer Association statements have recommended routine follow-up after curative gastrectomy from oncological, gastroenterological, research, and pastoral aspects, despite a lack of evidence supporting prolonged survival [5]. Japanese treatment guidelines for gastric cancer also recommend routine follow-up after curative gastrectomy [6].

Theoretically, the earlier that recurrence of gastric cancer is detected, the better the survival outcome, because treatment can begin while the tumor burden is relatively small [7]. This theory seems true for hepatic metastasis, 
with reported 5-year survival rates following resection for such cases with limited metastases of $11.0-20.8 \%[8,9]$. Consequently, surgeons who believe in the efficacy of routine follow-up programs generally recommend them with the aim of finding recurrent disease as early as possible, preferably before patients show tumor-associated symptoms. Nevertheless, it remains unproven whether patients with asymptomatic recurrence have better survival outcomes than those with symptomatic recurrence. This is possibly because the previous studies analyzed peritoneal and nonperitoneal cases of recurrence together, despite the documented differences in treatment strategies and efficacies $[10,11]$. Indeed, nonperitoneal recurrence can be treated and potentially even cured by surgery if it is detected early enough, whereas chemotherapy is the only treatment option for peritoneal recurrence even if it is detected before symptom presentation [12]. Therefore, the impact of routine follow-up might be different between peritoneal and nonperitoneal recurrences.

In this study we compared survival outcomes of patients with symptomatic and asymptomatic recurrence to clarify whether early detection of recurrence by imaging modalities could affect outcomes. We also compared patients with peritoneal recurrence and patients with nonperitoneal recurrence separately, to elucidate the recurrence pattern for which early detection is beneficial in terms of survival outcome.

\section{Methods}

\section{Patients}

Patients who underwent curative gastric resection (R0 surgery) for primary gastric cancer from September 2002 to December 2014 at Shizuoka Cancer Center were identified from a prospectively maintained database. Among 3274 patients, we excluded those with histological type other than adenocarcinoma $(n=67)$, with other cancer ( $n=381)$, who had received chemotherapy $(n=56)$ or radiation therapy $(n=1)$ before gastrectomy, and with pathological stage I cancer $(n=1756)$. Of the remaining 1036 patients, 218 with recurrent disease as of January 2016 were included in the present study. The data collection and analysis were approved by the Institutional Review Board of Shizuoka Cancer Center (approval no. 27-J167-27-1-3). Gastrectomy and lymph node dissection were performed according to the Japanese gastric cancer treatment guidelines [6, 13]. Pathological tumor depth, nodal status, and curability of surgery were assigned according to the Union for International Cancer Control classification, seventh edition [14].

\section{Follow up}

Patients who have undergone curative gastric resection for gastric cancer generally receive regular clinical follow-up according to the Japanese gastric cancer treatment guidelines $[6,13]$. Briefly, patients with advanced gastric cancer are checked every 3 months during the first 3 years and every 6 months thereafter until 5 years after the gastrectomy, and patients undergoing adjuvant chemotherapy visit the hospital every 2-6 weeks during treatment. During these visits, patients are interviewed on interim history, and undergo a physical examination and blood tests, including serum tumor marker assays. Abdominal computed tomography or ultrasonography is performed every 6 months for the first 3 years and every year thereafter. Endoscopic examinations are performed every 1 or 2 years on a patient-by-patient basis.

\section{Definition of recurrence}

All recurrences were diagnosed on the basis of imaging or pathological findings. When imaging findings were used for definitive diagnosis, the date of imaging examination was defined as the date of recurrence. When recurrence was ultimately diagnosed according to pathological findings, the date when an imaging modality showed abnormal findings for the first time was defined as the date of recurrence. The patterns of recurrence were categorized as peritoneal, locoregional, hematogenous, and distant lymph node recurrences. We defined nonperitoneal recurrence as cases showing new lesions of each organ or new/increasing-in-size lymph nodes of more than $10 \mathrm{~mm}$ in diameter. The definition of peritoneal recurrence was massive ascites or obvious peritoneal nodules on imaging. When slight ascites or unclear peritoneal nodules were found, we diagnosed peritoneal recurrence on the basis of pathological findings obtained by surgery or aspiration. Patients were stratified into peritoneal and nonperitoneal recurrence groups according to the recurrence patterns. Patients with multiple recurrence sites were assigned to the peritoneal recurrence group as long as they had peritoneal recurrence; otherwise they were assigned to the nonperitoneal recurrence group.

\section{Treatment after recurrence}

After detection of recurrence, patients received chemotherapy, additional surgery, or best supportive care. Additional surgery was performed after approval in a multidisciplinary team meeting if curative resection of recurrent tumor was expected. Additional surgical procedures performed in the present study included 
metastasectomy for liver, lung, and lymph node metastasis, and surgery for locoregional recurrence.

\section{Comparison between symptomatic and asymptomatic groups}

We compared clinicopathological characteristics and survival outcomes between patients who had any symptoms at the date of recurrence (symptomatic group, $n=101$ ) and those with no symptoms (asymptomatic group, $n=117$ ). The most frequently observed symptom at the time of recurrence was abdominal pain $(33.7 \%)$, followed by anorexia (20.8\%), backache (10.9\%), vomiting (10.9\%), fever $(8.9 \%)$, and abdominal distension (7.9\%). Survival outcomes compared between the groups included time to recurrence, overall survival after gastrectomy, and overall survival after recurrence.

In addition, we did the same analysis for patients with peritoneal recurrence and patients with nonperitoneal recurrence separately.

\section{Statistical analysis}

All continuous variables are presented as the median and range. Statistical analyses were performed with the Fisher exact test, the $t$ test, and the Mann-Whitney test. Survival data were analyzed by the Kaplan-Meier method, and the log-rank test was used to compare groups. We also conducted multivariate analysis for overall survival, with adjustment for symptoms, age, sex, comorbidity, surgical procedure, histological type, pathological stage, and peritoneal recurrence. The Cox proportional hazards model was used to calculate the hazard ratio between the groups. Twosided $P<0.05$ was considered significant. All statistical analyses were conducted with $\mathrm{R}$ Statistics version 3.2.0.

\section{Results}

The clinicopathological characteristics of the patients at gastrectomy are listed in Table 1 . The incidence of differentiated types was significantly greater in the asymptomatic group than in the symptomatic group $(P<0.001)$, but no intergroup difference was found for surgical factors, tumor size, pathological stage, or adjuvant therapy. The main follow-up modalities that provided an opportunity to detect asymptomatic recurrence were 5 -mm-slice computed tomography $(64.1 \%)$, followed by tumor marker assays $(18.8 \%)$, ultrasonography $(10.3 \%)$, analysis of laboratory data (3.4\%), and endoscopy (1.7\%). Table 2 details the patterns of recurrence; the most frequent pattern was peritoneal recurrence $(40.8 \%)$, followed by hematogenous recurrence $(38.1 \%)$, and then distant lymph node
Table 1 Clinicopathological characteristics

\begin{tabular}{|c|c|c|c|}
\hline & $\begin{array}{l}\text { Asymptomatic } \\
\text { patients } \\
(n=117)\end{array}$ & $\begin{array}{l}\text { Symptomatic } \\
\text { patients } \\
(n=101)\end{array}$ & $P$ \\
\hline Age (years) & & & 0.092 \\
\hline Median & 69 & 66 & \\
\hline Range & $30-85$ & $35-85$ & \\
\hline Sex & & & 0.122 \\
\hline Male & 86 & 64 & \\
\hline Female & 31 & 37 & \\
\hline $\begin{array}{l}\text { Body mass index } \\
\left(\mathrm{kg} / \mathrm{m}^{2}\right)\end{array}$ & & & 0.617 \\
\hline Median & 22.2 & 22.8 & \\
\hline Range & $14.3-32.9$ & $15.2-30.5$ & \\
\hline $\begin{array}{l}\text { ECOG performance } \\
\text { status }\end{array}$ & & & 0.463 \\
\hline 0 or 1 & 117 & 100 & \\
\hline 2 or 3 & 0 & 1 & \\
\hline Comorbidity & & & 0.277 \\
\hline Yes & 55 & 40 & \\
\hline No & 62 & 61 & \\
\hline Surgical procedure & & & 0.480 \\
\hline Total gastrectomy & 52 & 53 & \\
\hline $\begin{array}{l}\text { Distal } \\
\text { gastrectomy }\end{array}$ & 63 & 47 & \\
\hline $\begin{array}{l}\text { Proximal } \\
\text { gastrectomy }\end{array}$ & 2 & 1 & \\
\hline $\begin{array}{l}\text { Combined organ } \\
\text { resection }\end{array}$ & & & 0.272 \\
\hline Yes & 45 & 47 & \\
\hline No & 72 & 54 & \\
\hline $\begin{array}{l}\text { Extent of } \\
\text { lymphadenectomy }\end{array}$ & & & 0.732 \\
\hline$<\mathrm{D} 2$ & 21 & 20 & \\
\hline$\geq \mathrm{D} 2$ & 96 & 81 & \\
\hline $\begin{array}{l}\text { Postoperative } \\
\text { complication }\end{array}$ & & & 0.413 \\
\hline Yes & 53 & 40 & \\
\hline No & 64 & 61 & \\
\hline Size $(\mathrm{mm})$ & & & 0.195 \\
\hline Median & 55 & 60 & \\
\hline Range & $8-230$ & $17-205$ & \\
\hline Histological type & & & $<0.001$ \\
\hline Differentiated & 67 & 32 & \\
\hline Undifferentiated & 50 & 69 & \\
\hline Primary tumor & & & 0.051 \\
\hline $\mathrm{T} 1$ & 8 & 10 & \\
\hline $\mathrm{T} 2$ & 11 & 5 & \\
\hline $\mathrm{T} 3$ & 66 & 43 & \\
\hline $\mathrm{T} 4$ & 32 & 43 & \\
\hline $\begin{array}{l}\text { Regional lymph } \\
\text { nodes }\end{array}$ & & & 0.159 \\
\hline N0 & 11 & 12 & \\
\hline
\end{tabular}


Table 1 continued

\begin{tabular}{llll}
\hline & $\begin{array}{l}\text { Asymptomatic } \\
\text { patients } \\
(n=117)\end{array}$ & $\begin{array}{l}\text { Symptomatic } \\
\text { patients } \\
(n=101)\end{array}$ & $P$ \\
\hline N1 & 23 & 9 & \\
N2 & 29 & 29 & 0.812 \\
N3 & 54 & 51 & \\
Distant metastasis & & & \\
M0 & 106 & 93 & \\
M1 & 11 & 8 & \\
Pathological stage & & 25 & \\
II & 43 & 68 & \\
III & 63 & 8 & \\
IV & 11 & & \\
Adjuvant & & 42 & \\
chemotherapy & & 59 & \\
Yes & 39 & 78 &
\end{tabular}

ECOG Eastern Cooperative Oncology Group

recurrence $(34.9 \%)$. Peritoneal recurrence was more frequently observed in the symptomatic group than in the asymptomatic group (62.4\% vs $22.2 \%, P<0.001)$. Of 89 patients with peritoneal recurrence, this was pathologically diagnosed in 28 patients who underwent surgery and 8 patients who underwent aspiration of ascites. Treatment after the detection of recurrence was significantly different between the groups $(P=0.006)$. Chemotherapy or additional surgery was frequently performed in the asymptomatic group. Additional surgery was performed for liver metastasis $(n=7)$, lung metastasis $(n=1)$, lymph node metastasis $(n=2)$, or local recurrence $(n=1)$. Of 11 additional surgical procedures, 10 were performed for patients in the asymptomatic group with nonperitoneal recurrence.

Survival curves are shown in Fig. 1. The median time to recurrence was shorter in the asymptomatic group than in the symptomatic group (12.7 months vs 18.9 months; $P<0.001)$ and the median survival time after recurrence was longer (18.7 months vs 7.5 months, respectively; $P<0.001)$. Of note, the median overall survival time after gastrectomy was not significantly different between the groups (30.1 months for asymptomatic recurrence vs 30.0 months for symptomatic recurrence; $P=0.132$ ). In multivariate analysis, overall survival after gastrectomy was not significantly different between the groups (hazard ratio $0.86 ; P=0.402$ ).

In patients with peritoneal recurrence, the outcomes were similar: shorter time to recurrence (13.7 months vs 20.7 months; $P=0.007)$ and longer survival time after recurrence ( 8.3 months vs 7.0 months; $P=0.042$ ) in the
Table 2 Details and treatment of recurrent gastric cancer after curative gastrectomy

\begin{tabular}{|c|c|c|c|}
\hline & $\begin{array}{l}\text { Asymptomatic } \\
\text { patients } \\
(n=117)\end{array}$ & $\begin{array}{l}\text { Symptomatic } \\
\text { patients } \\
(n=101)\end{array}$ & $P$ \\
\hline \multicolumn{3}{|l|}{ Site of metastases } & $<0.001$ \\
\hline Single & 91 & 38 & \\
\hline Multiple & 26 & 63 & \\
\hline \multicolumn{4}{|l|}{ Pattern of recurrence } \\
\hline Peritoneal & 26 & 63 & \\
\hline Nonperitoneal & 91 & 38 & \\
\hline \multicolumn{4}{|l|}{ Detail (duplication) } \\
\hline Peritoneal & 26 & 63 & $<0.001$ \\
\hline Locoregional & 6 & 8 & 0.422 \\
\hline Hematogenous & 53 & 30 & 0.025 \\
\hline $\begin{array}{l}\text { Distant lymph } \\
\text { node }\end{array}$ & 52 & 24 & 0.002 \\
\hline \multicolumn{4}{|l|}{ Recurrence therapy } \\
\hline All cases & & & 0.006 \\
\hline Chemotherapy & 80 & 63 & \\
\hline $\begin{array}{l}\text { Additional } \\
\text { surgery }\end{array}$ & 10 & 1 & \\
\hline BSC & 27 & 37 & \\
\hline $\begin{array}{l}\text { Peritoneal } \\
\text { recurrence }\end{array}$ & & & 0.095 \\
\hline Chemotherapy & 20 & 36 & \\
\hline $\begin{array}{l}\text { Additional } \\
\text { surgery }\end{array}$ & 0 & 0 & \\
\hline BSC & 6 & 27 & \\
\hline $\begin{array}{l}\text { Nonperitoneal } \\
\text { recurrence }\end{array}$ & & & 0.321 \\
\hline Chemotherapy & 60 & 27 & \\
\hline $\begin{array}{l}\text { Additional } \\
\text { surgery }\end{array}$ & 10 & 1 & \\
\hline BSC & 21 & 10 & \\
\hline
\end{tabular}

$B S C$ best supportive care

asymptomatic group compared with the symptomatic group, and comparable overall survival time after gastrectomy (25.0 months vs 33.4 months; $P=0.187$ ) between the groups (Fig. 2). In multivariate analysis for overall survival after gastrectomy in patients with peritoneal recurrence, there was no significant differences between the groups (hazard ratio 1.60; $P=0.074$ ).

Our separate analysis among patients with nonperitoneal recurrence showed no significant difference in the time to recurrence between the asymptomatic group and the symptomatic group (12.2 months vs 15.2 months; $P=0.062$ ), but the survival time after recurrence was significantly longer in the asymptomatic group than in the symptomatic group (20.8 months vs 7.5 months; $P<0.001$ ) (Fig. 3). Therefore, the overall survival time 
a

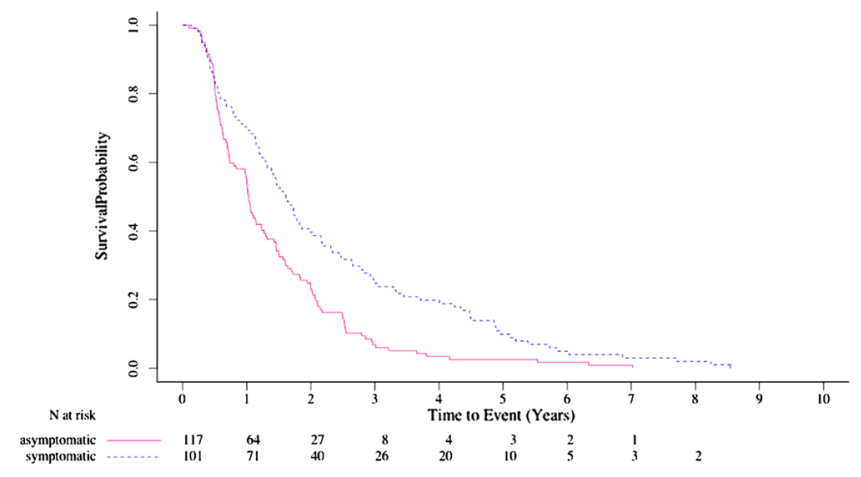

C

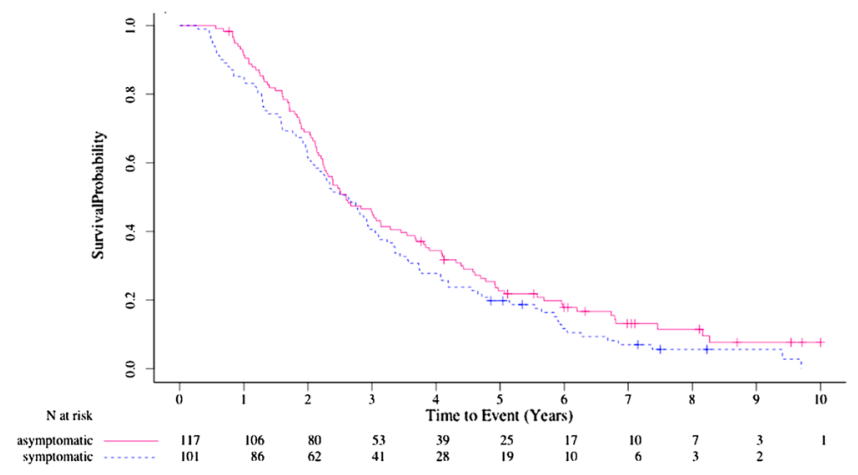

Fig. 1 a Time to recurrence [hazard ratio (HR) 1.71, 95\% confidence interval (CI) 1.30-2.26; $p<0.001$ ], b overall survival after recurrence (HR $0.38,95 \%$ CI $0.29-0.52 ; p<0.001$ ), and $\mathbf{c}$ overall survival (HR

after gastrectomy was significantly greater in asymptomatic patients with nonperitoneal recurrence than in symptomatic patients (35.9 months vs 24.0 months; $P=0.039$ ). In multivariate analysis, the absence of symptoms in patients with nonperitoneal recurrence was significantly associated with prolonged overall survival after gastrectomy (hazard ratio $0.55 ; P=0.008$ ) (Table 3).

\section{Discussion}

The present study showed that the time after recurrence was significantly longer in asymptomatic patients undergoing routine follow-up after gastrectomy for gastric cancer than in patients showing symptoms of recurrence, whereas the overall survival time after gastrectomy was not significantly different between these groups. This indicated that asymptomatic recurrence was generally found sooner after surgery, and was associated with longer survival after recurrence; however, asymptomatic recurrence did not show survival benefit.

Our results are consistent with those of previous studies, most of which analyzed a retrospective series and showed b

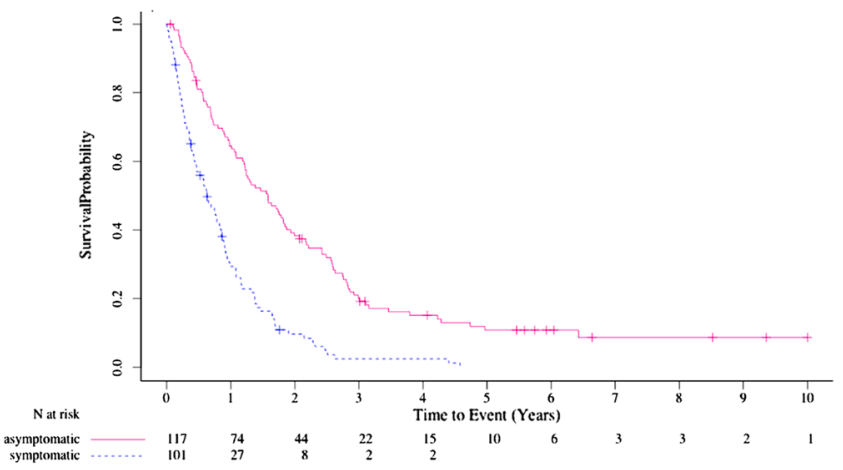

$0.81,95 \%$ CI $0.61-1.07 ; p=0.132$ ) for patients in the asymptomatic and symptomatic groups

no survival benefit of early detection of recurrence, based on indirect evaluation of the effect of follow-up or no follow-up on survival by comparing survival between the presence or absence of symptoms at the time of recurrence $[10,11,15,16]$. In contrast, Tan and So [17] investigated the follow-up schedule itself for its effect on patient outcome by comparing long-term survival between patients who received intensive follow-up, which included computed tomography more than once every 12 months, and those who received regular follow-up. They reported no difference in the length of survival, although recurrences were detected earlier in the intensive follow-up group [17]. Park et al. [18] also reported the benefit of suitable surveillance intervals for overall survival after curative surgery for gastric cancer, concluding that once a year is sufficient for follow-up imaging studies and that shortening the surveillance interval is not necessary for improving survival and is not recommended. Differently from the present study, none of these previous studies separated patients into those with peritoneal recurrence and those with nonperitoneal recurrence when analyzing survival outcome and symptoms at the time of recurrence. Thus, to the best of our knowledge, this is the first report 
a
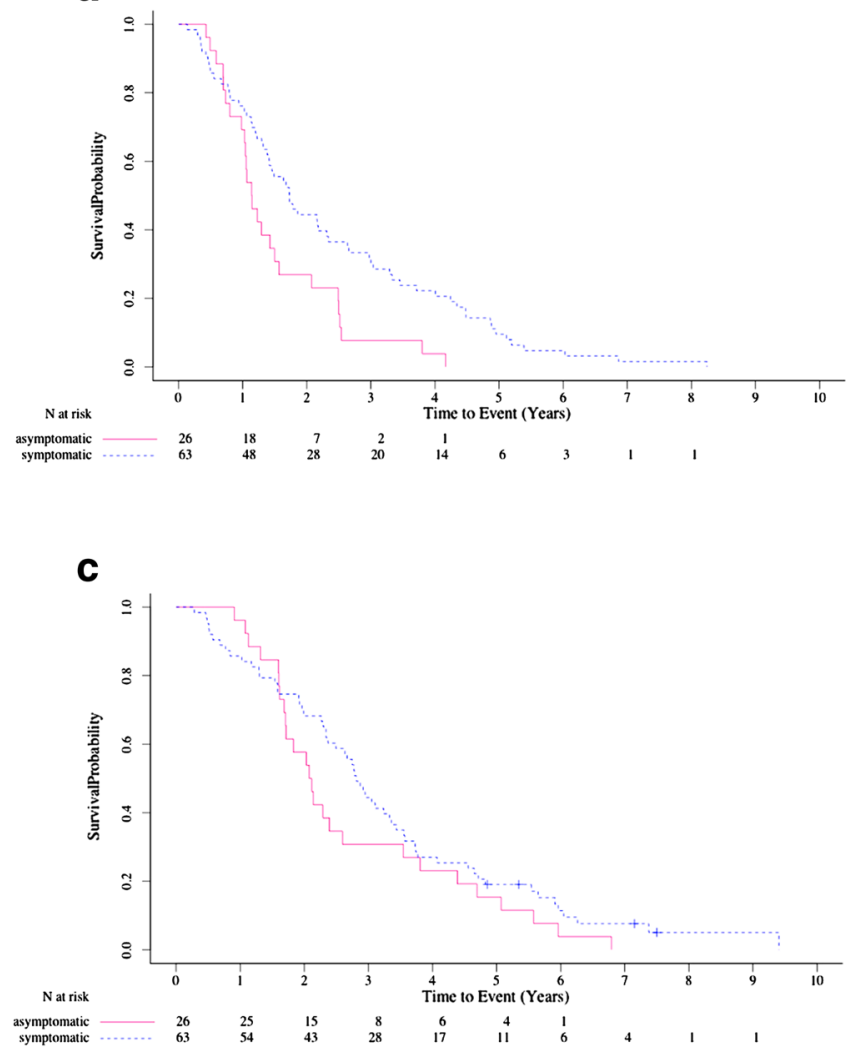

Fig. 2 a Time to recurrence in patients with peritoneal recurrence [hazard ratio (HR) 1.94, 95\% confidence interval (CI) 1.20-3.15; $p=0.007]$, b overall survival after recurrence in patients with peritoneal recurrence (HR 0.59, 95\% CI 0.35-0.98; $p=0.042$ ), and

showing the impact of early detection of recurrence on survival outcome in patients with nonperitoneal recurrence, and we found that the presence of symptoms at follow-up was associated with poor survival outcome.

In Japan, although former treatment guidelines did not mention follow-up protocols, surgeons generally followed up patients for at least for 5 years after gastrectomy with regular imaging examinations [19]. In the latest, fourth edition of the Japanese gastric cancer treatment guidelines published in 2014, the follow-up protocol was described for the first time, and includes annual imaging examination for early gastric cancer, and biannual examination for the first 3 years after gastrectomy for advanced gastric cancer and annual imaging check-up thereafter [6]. The guidelines also recommend regular visits to outpatient clinics, measurement of tumor markers, and endoscopy, on the basis of the cancer stage and the surgical procedure performed. The Japanese Gastric Cancer Association highlights the efficacy of serum tumor markers [20] and $\left[{ }^{18} \mathrm{~F}\right]$ fluoro-2-deoxyglucose positron emission tomography [21] for detection of recurrence and distant metastasis. However, although the guidelines also state that follow-up at the outpatient clinic b

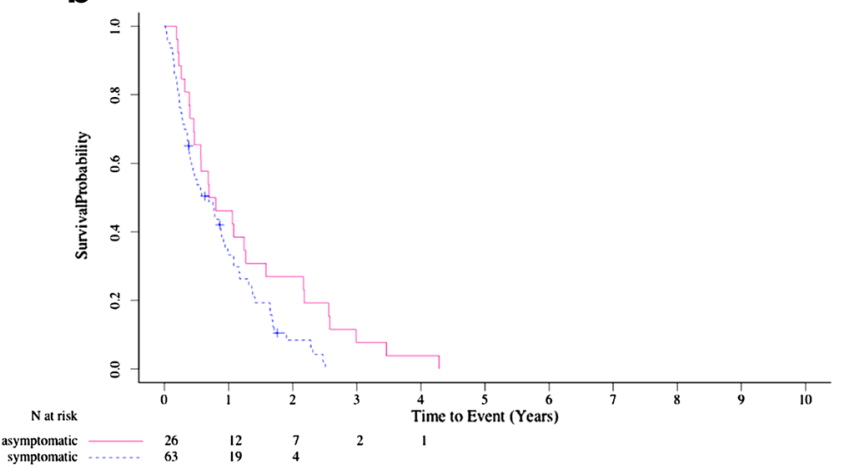

c overall survival in patients with peritoneal recurrence (HR 1.37, 95\% CI $0.86-2.18 ; p=0.187$ ) for patients in the asymptomatic and symptomatic groups

could be helpful, there is a lack of evidence linking such follow-up to increased survival. Our results support the concept of the follow-up protocol depicted in the guidelines because they show the survival benefit of early detection of nonperitoneal recurrence with imaging modalities before patients show any symptoms.

Our findings therefore suggest that detection of nonperitoneal recurrence before the appearance of symptoms may provide survival benefit following gastrectomy for gastric cancer. Although the asymptomatic groups showed better survival time after recurrence in both subsets, the difference in survival time after recurrence between the groups was much larger in patients with nonperitoneal recurrence than in those with peritoneal recurrence. Symptomatic recurrence tended to more progressive stages and more extended surgery, although there were no significant differences in clinicopathological characteristics. However, when we stratified patients with nonperitoneal recurrence into patients with stage II cancer, the overall survival time after gastrectomy was greater in asymptomatic patients with nonperitoneal recurrence than in symptomatic patients (37.0 months vs 16.4 months; 


\section{a}

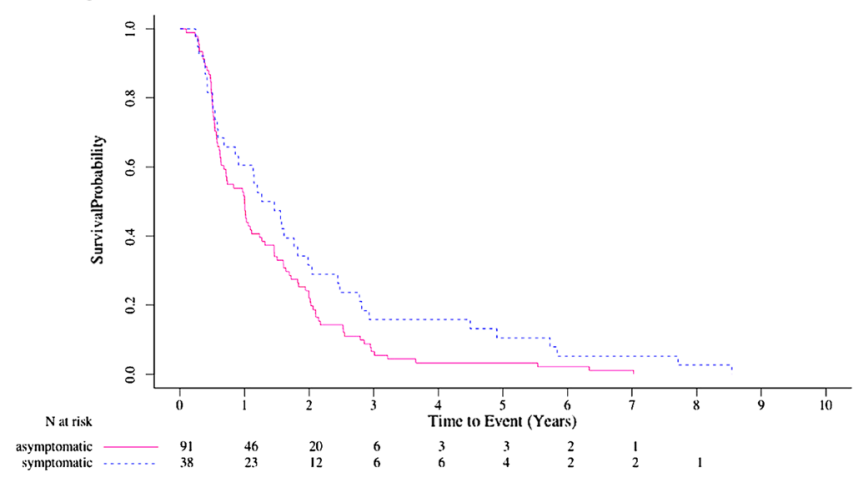

\section{C}

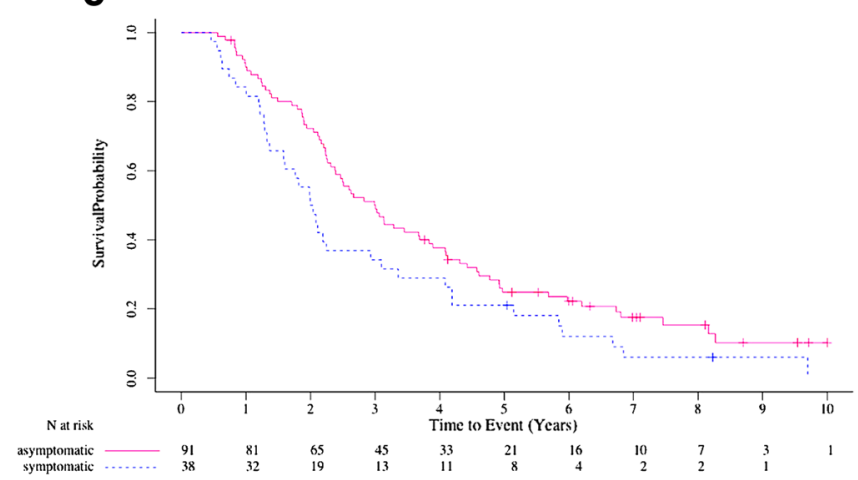

Fig. 3 a Time to recurrence in patients with nonperitoneal recurrence [hazard ratio (HR) 1.45, 95\% confidence interval (CI) 0.98-2.15; $p=0.062]$, b overall survival after recurrence in patients with nonperitoneal recurrence (HR $0.39,95 \%$ CI $0.22-0.51 ; p<0.001$ ),

Table 3 Multivariate analysis for overall survival in patients with nonperitoneal recurrence

\begin{tabular}{llll}
\hline & HR & $95 \%$ CI & $P$ \\
\hline Symptom: asymptomatic recurrence & 0.55 & $0.36-0.82$ & 0.008 \\
Age (years) & 1.04 & $1.01-1.06$ & 0.003 \\
Sex: male & 1.07 & $0.66-1.73$ & 0.796 \\
Comorbidity & 1.41 & $0.93-2.14$ & 0.108 \\
Surgical procedure & & & \\
$\quad$ Distal gastrectomy & 1 & & \\
Total gastrectomy & 1.00 & $0.67-1.49$ & 0.981 \\
$\quad$ Proximal gastrectomy & 3.58 & $0.82-15.63$ & 0.090 \\
Histological type: Undifferentiated & 0.90 & $0.59-1.38$ & 0.628 \\
Pathological stage & & & \\
II & 1 & & \\
III & 1.70 & $1.06-2.73$ & 0.027 \\
IV & 2.22 & $1.14-4.34$ & 0.019 \\
\hline CI
\end{tabular}

$C I$ confidence interval, $H R$ hazard ratio

$P=0.419)$. Therefore, the detection of recurrence before symptom appearance has implications for survival benefit. We also adjusted the covariates for overall survival using

\section{b}

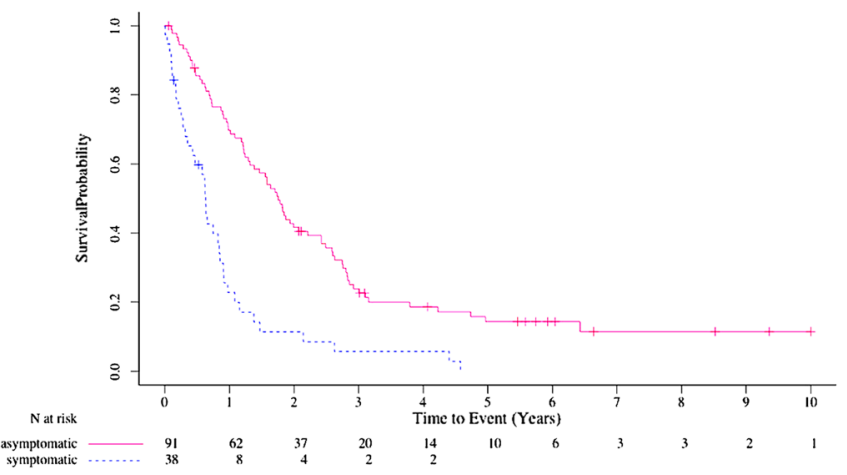

and $\mathbf{c}$ overall survival in patients with nonperitoneal recurrence (HR $0.66,95 \%$ CI $0.44-0.98 ; p=0.039$ ) for patients in the asymptomatic and symptomatic groups

multivariate analysis, and consequently the relationship between symptoms and survival did not differ. Additional surgery is cited as a possible reason for this finding and might therefore play a key role in providing better survival outcomes. Indeed, ten patients with nonperitoneal recurrence in our asymptomatic group $(8.5 \%)$ underwent additional surgery, and showed a median survival time after recurrence and a 5-year survival rate after recurrence of 56.8 months and $60.0 \%$ respectively. On the other hand, only one patient $(1.0 \%)$ in the symptomatic group underwent surgery. Therefore, regular follow-up to detect nonperitoneal recurrence before symptom presentation is recommended.

Overall survival was not different between the asymptomatic and symptomatic groups in the present analysis when we selected patients with peritoneal recurrence. However, we assume that it would be difficult to obtain survival benefit even if peritoneal recurrence were detected early, because additional surgery, which plays an important role in prolonging survival in cases of nonperitoneal recurrence, was generally not indicated in peritoneal recurrence even if it was detected before symptom 
presentation. In the present study, none of the patients with peritoneal recurrence received additional surgery, and chemotherapy, with which the chance of cure was slim $[22,23]$, was a main treatment option. Therefore, the benefits to start treatment early are limited, and the implication of follow-up for detection of peritoneal recurrence is less meaningful.

Identifying patients at higher risk of nonperitoneal recurrence after curative gastrectomy could provide survival benefit to patients by offering more intensive postoperative follow-up, on the basis of our present findings. It is well known that undifferentiated-type and serosa-invasive adenocarcinoma is frequently associated with peritoneal recurrence [24], whereas differentiated-type adenocarcinoma is related to nonperitoneal recurrence [25]. If we can predict a similar recurrence pattern with high accuracy, we could offer the most suitable follow-up schedule to each patient accordingly.

The present study has limitations. First, this study is retrospective and was performed at a single institution. Second, it is unclear whether symptoms at the time of recurrence are distinctly related to recurrence of cancer. Finally, the optimal follow-up schedule remains obscure because the present study did not compare follow-up protocols directly. A comparative study, hopefully for patients at higher risk of nonperitoneal recurrence, is warranted to establish more effective and personalized follow-up protocols.

\section{Conclusion}

The presence of symptoms at the time of recurrence after curative gastrectomy for gastric cancer did not affect longterm survival. However, detection of nonperitoneal recurrence before the appearance of symptoms provided survival benefit. These findings argue for regular follow-up of gastric cancer patients using imaging modalities.

Acknowledgements This research was supported in part by the Practical Research for Innovative Cancer Control of the Japan Agency for Medical Research and Development (15ck0106043h0002).

\section{Compliance with ethical standards}

Conflict of Interest The authors declare that they have no conflict of interest.

Ethical standards All procedures followed were in accordance with the ethical standards of the responsible committee on human experimentation (institutional and national) and with the Helsinki Declaration of 1964 and later versions.

Informed consent Informed consent or a substitute for it was obtained from all patients before their being included in the study.

\section{References}

1. Ferlay J, Soerjomataram I, Dikshit R, Eser S, Mathers C, Rebelo $\mathrm{M}$, et al. Cancer incidence and mortality worldwide: sources, methods and major patterns in GLOBOCAN 2012. Int J Cancer. 2015;136:E359-86.

2. Shiraishi N, Inomata M, Osawa N, Yasuda K, Adachi Y, Kitano $\mathrm{S}$. Early and late recurrence after gastrectomy for gastric carcinoma. Univariate and multivariate analyses. Cancer. 2000;89:255-61.

3. Whiting J, Sano T, Saka M, Fukagawa T, Katai H, Sasako M. Follow-up of gastric cancer: a review. Gastric Cancer. 2006;9:74-81.

4. Waddell T, Verheij M, Allum W, Cunningham D, Cervantes A, Arnold D. Gastric cancer: ESMO-ESSO-ESTRO clinical practice guidelines for diagnosis, treatment and follow-up. Eur J Surg Oncol. 2014;40:584-91.

5. Baiocchi GL, D’Ugo D, Coit D, Hardwick R, Kassab P, Nashimoto A, et al. Follow-up after gastrectomy for cancer: the Charter Scaligero Consensus Conference. Gastric Cancer. 2016;19:15-20.

6. Japanese Gastric Cancer Association. Japanese gastric cancer treatment guidelines 2014 (ver. 4). Gastric Cancer. 2016. doi:10. 1007/s10120-016-0622-4.

7. Hasegawa H, Fujitani K, Nakazuru S, Hirao M, Yamamoto K, Mita E, et al. Optimal treatment change criteria for advanced gastric cancer with non-measurable peritoneal metastasis: symptom/tumor marker-based versus CT-based. Anticancer Res. 2014;34:5169-74.

8. Sakamoto Y, Sano T, Shimada K, Esaki M, Saka M, Fukagawa T, et al. Favorable indications for hepatectomy in patients with liver metastasis from gastric cancer. J Surg Oncol. 2007;95:534-9.

9. Cheon SH, Rha SY, Jeung HC, Im CK, Kim SH, Kim HR, et al. Survival benefit of combined curative resection of the stomach (D2 resection) and liver in gastric cancer patients with liver metastases. Ann Oncol. 2008;19:1146-53.

10. Kodera Y, Ito S, Yamamura Y, Mochizuki Y, Fujiwara M, Hibi $\mathrm{K}$, et al. Follow-up surveillance for recurrence after curative gastric cancer surgery lacks survival benefit. Ann Surg Oncol. 2003;10:898-902.

11. Eom BW, Ryu KW, Lee JH, Choi IJ, Kook MC, Cho SJ, et al. Oncologic effectiveness of regular follow-up to detect recurrence after curative resection of gastric cancer. Ann Surg Oncol. 2011;18:358-64.

12. Wu CW, Lo SS, Shen KH, Hsieh MC, Chen JH, Chiang JH, et al. Incidence and factors associated with recurrence patterns after intended curative surgery for gastric cancer. World J Surg. 2003;27:153-8.

13. Japanese Gastric Cancer Association. Japanese classification of gastric carcinoma: 3rd English edition. Gastric Cancer. 2011;14:101-12.

14. Sobin LH, Gospodarowicz MK, Wittekind C. TNM classification of malignant tumours. 7th ed. Hoboken: Wiley-Blackwell; 2010.

15. Bennett J, Gonen M, D’Angelica M, Jaques D, Brennan M, Coit D. Is detection of asymptomatic recurrence after curative resection associated with improved survival in patients with gastric cancer? J Am Coll Surg. 2005;201:503-10.

16. Bilici A, Salman T, Oven Ustaalioglu BB, Unek T, Seker M, Aliustaoglu M, et al. The prognostic value of detecting symptomatic or asymptomatic recurrence in patients with gastric cancer after a curative gastrectomy. J Surg Res. 2013;180:e1-9.

17. Tan IT, So BYJ. Value of intensive follow-up of patients after curative surgery for gastric carcinoma. J Surg Oncol. 2007;96:503-6. 
18. Park CH, Park JC, Chung H, Shin SK, Lee SK, Cheong JH, et al. Impact of the surveillance interval on the survival of patients who undergo curative surgery for gastric cancer. Ann Surg Oncol. 2016;23:539-45.

19. Japanese Gastric Cancer Association. Japanese gastric cancer treatment guidelines 2010 (ver. 3). Gastric Cancer. 2011;14:113-23.

20. Shimada H, Noie T, Ohashi M, Oba K, Takahashi Y. Clinical significance of serum tumor markers for gastric cancer: a systematic review of literature by the Task Force of the Japanese Gastric Cancer Association. Gastric Cancer. 2014;17:26-33.

21. Shimada H, Okazumi S, Koyama M, Murakami K. Japanese Gastric Cancer Association Task Force for Research Promotion: clinical utility of ${ }^{18}$ F-fluoro-2-deoxyglucose positron emission tomography in gastric cancer. A systematic review of the literature. Gastric Cancer. 2011;14:13-21.
22. Sadeghi B, Arvieux C, Glehen O, Beaujard AC, Rivoire M, Baulieux J, et al. Peritoneal carcinomatosis from non-gynecologic malignancies: results of the EVOCAPE 1 multicentric prospective study. Cancer. 2000;88:358-63.

23. Ohtsu A, Shimada Y, Shirao K, Boku N, Hyodo I, Saito H, et al. Randomized phase III trial of fluorouracil alone versus fluorouracil plus cisplatin versus uracil and tegafur plus mitomycin in patients with unresectable, advanced gastric cancer: the Japan Clinical Oncology Group study (JCOG9205). J Clin Oncol. 2003;21:54-9.

24. Miki Y, Tokunaga M, Tanizawa Y, Bando E, Kawamura T, Terashima M. Staging laparoscopy for patients with cM0, type 4, and large type 3 gastric cancer. World J Surg. 2015;39:2742-7.

25. D'Angelica M, Gonen M, Brennan MF, Turnbull AD, Bains M, Karpeh MS. Patterns of initial recurrence in completely resected gastric adenocarcinoma. Ann Surg. 2004;240:808-16. 